\title{
Determining the likelihood of incidents caused by human error during dynamic positioning drilling operations
}

\author{
Zaloa Sanchez-Varela, ${ }^{1,2 *}$ (D) David Boullosa-Falces, ${ }^{2}$ Juan L. Larrabe-Barrena, ${ }^{2}$ and \\ Miguel A. Gomez-Solaeche ${ }^{2}$ \\ ${ }^{1}$ Faculty of Maritime Studies, University of Split, Split, Croatia. \\ ${ }^{2}$ Faculty of Engineering in Bilbao, University of the Basque Country (UPV/EHU), Bilbao, Spain. \\ *Corresponding author. E-mail: zsanchezv@pfst.hr
}

Received: 5 December 2020; Accepted: 4 March 2021; First published online: 23 March 2021

Keywords: dynamic positioning (DP), offshore, risk minimisation, human factor

\begin{abstract}
The probability of a human-caused incident occurring during dynamic positioning (DP) drilling operations is determined in this paper using binary logistic regression models built with data on 42 incidents that took place during the period 2011-2015. For each case, a range of variables characterising the configuration of the DP system, weather conditions and water depth are taken into account. These variables are taken into account to develop a logistic regression model that shows the likelihood of an incident being caused by human error. The results obtained show that human-based incidents are significantly more likely to occur when there is a lower usage of thrusters. These results are useful for focusing our attention on variables that may be associated with incidents attributable to human error, as well as for setting operational limits that could help to prevent these incidents and improve safety during these operations.
\end{abstract}

\section{Introduction}

A dynamic positioning (DP) system allows a drilling unit to maintain position and heading, while at the same time making sure the angle of the riser (the line connecting the platform with the drilling bit) is as close as possible to zero. Despite the high safety standards of the offshore drilling industry, on occasions there have been accidents with severe consequences. Images of the explosions on the Deepwater Horizon in the Gulf of Mexico and Piper Alpha in the North Sea remain in the collective memory (Singh et al., 2010; Theophilus et al., 2017). These are examples of accidents that occurred due to loss of position during drilling operations. Investigations into fatalities and/or other accidents are published by the U.S. Bureau of Safety and Environmental Enforcement (2019); however, less serious incidents are rarely the subject of such an investigation and instead are resolved within the company (Theophilus et al., 2017). Indeed, lists of incidents are considered highly confidential and are rarely made public or accessible to researchers. Nonetheless, it is known that in the oil and gas industry in general (Kariuki and Löwe, 2007; Manca and Brambilla, 2012), and the offshore drilling sector in particular (Hogenboom et al., 2020), incidents due to direct and indirect human factor failings are not rare.

It is important, in safety terms, to identify the potential hazards associated with given operations, and determine the probability of incidents occurring and their possible outcomes and consequences. This approach is commonly known as quantitative risk assessment (QRA) (Kristiansen, 2005). Although QRA was initially applied to nuclear facilities (Levine and Rasmussen, 1984), it has since been extensively applied in other industries, including the oil and gas industry, where the results have been very satisfactory

(C) The Royal Institute of Navigation 2021. This is an Open Access article, distributed under the terms of the Creative Commons Attribution licence (http://creativecommons.org/licenses/by/4.0/), which permits unrestricted re-use, distribution, and reproduction in any medium, provided the original work is properly cited. 
(Kalantarnia et al., 2010). Notably, inadequate risk management was found to be a contributory cause in $27.1 \%$ of all types of maritime accidents (Acejo et al., 2018).

Over the years, the idea of QRA has been improved by the development of various methodologies. Some examples of these are hazard and operability studies (HAZOPs), failure mode and effect analysis, fault tree analysis and event tree analysis (Khan and Abbasi, 1998). Another method which has been extensively used for risk analysis of DP incidents is the Bayesian network, a graphical model that represents the dependency between variables, using nodes and directed links, making it possible to show conditional probabilities for a set of variables (Ancione et al., 2020). This technique is widely applied in DP incident analysis; however, the parameters used for quantifying the associated risk generally depend on the best judgement of the person performing the analysis (Mkrtchyan et al., 2015).

Thanks to the high level of the protective measures taken to prevent catastrophic consequences, the frequency of accidents in the oil and gas industry can be considered low, and hence, though data on accidents are published, there is a limited volume of accident data available for analysis. That is why incidents and near-misses began to be used for updating risk analysis and management (Bier and Mosleh, 1990; Bier and Yi, 1995). Studies using this approach have been reported by Khakzad et al. (2014); Yang et al. (2015), and more recently, Arnaldo Valdes et al.(2018), Rebello et al. (2019) and Shengli and Yongtu (2019).

Precursor data for an incident is all the data that may influence a particular incident. When such a database is analysed, a specific pattern may be seen that could be used to predict an incident. This is the principle underlying the regression modelling technique used in this paper. Several publications have appeared in recent years documenting the use of regression modelling for predicting and preventing incidents in the transportation field. For example, in terrestrial transportation, logistic regression modelling was applied in the detection of traffic incidents (Agarwal et al., 2016) and their duration (Li et al., 2015). In the air transportation sector, always closely connected to the maritime industry in terms of safety, this statistical approach has been used for the prediction of human-error incidents (McFadden, 1997; Erjavac et al., 2018).

Nonetheless, to the best of our knowledge, very few publications can be found in the literature concerning the use of logistic regression modelling for the prediction of incidents in the maritime industry. The few exceptions include an article in which Hogenboom et al. (2020) used logistic regressions to explain the influence of human error on maritime incidents; while Boullosa-Falces et al. (2017) applied this method as part of a variable selection process before then constructing a prediction model. Further, Weng et al. (2018) used multinomial logistic regression to investigate the likelihood of occurrence of human errors, and thereby obtain a model based on meteorological conditions for predicting major accidents in shipping. Fiskin et al. (2020) used logistic regression to analyse the variables contributing to tugboat accidents.

\subsection{Elements of DP during drilling operations}

Drilling operations take place over a wellhead. The primary function of the DP system, known as the riser angle or riser-follow mode, is to maintain the position of the drilling vessel such that the riser/stack angle, containing the drill string, is close to zero, compensating for currents or tidal flow as necessary (Mao et al., 2019). This angle is that measured between the riser (on the top) and the wellhead or lower marine riser package (Bray, 2018). The riser difference angle is monitored through sensors located around the lower marine riser package by the dynamic positioning operator (DPO). The DPO is a certified officer of the watch who has completed a training and certification programme to be able to hold this position on board (The Nautical Institute, 2017). A watch circle system is created to enable the DPO to monitor the movements of the vessel. When the rig is moving, various levels of alarm are set to ensure the safety of the operations at all times (Mao et al., 2019).

The main risk in any DP operation is the loss of position, or excursion, during operations. The DPO should, therefore, react rapidly to correct or mitigate the consequences of any such loss (Hogenboom 
et al., 2020). The severity of these accidents is greater in adverse weather conditions. (Erol et al., 2018). The system for maintaining the position of the drilling riser consists of a closed-loop control function that receives information from sensors that measure wind, currents, heading and position. It sends a command to the propulsion units to counteract the forces that, according to the information available, tend to take the vessel out of position. The desired position is input by the DPO who supervises the operation through a human-machine interface, also known as the DP console. The central element is the controller, composed of computers or processors, which establishes two-way communication with all other DP elements via the vessel network.

To acquire information on the position of the rig, position reference systems (PRS) are used. Although on most vessels these are usually referred to as global positioning systems (GPS), in DP drilling operations there are several PRS which provide additional accuracy (Bray et al., 2015). Most commonly, drilling rigs select dual differential global navigation satellite systems (DGNSS) and hydroacoustic position reference (HPR) systems, usually of the long-baseline type. Taut wires are only used in shallow waters, this type of device not being available for deep waters (Bray, 2018).

The motion of the vessel is monitored with several sensors. Specifically, yawing is monitored with the help of one or more gyrocompasses that send information about the heading, while motion reference units (MRUs) provide information about surge and sway. Wind and currents are also monitored for direction and speed, and this information is sent to the controller. There are wind sensors in various positions onboard the rig, in order to avoid errors due to windshields, turbulence near structures etc. With all this information, the controller is able to predict the movement of the vessel, and send appropriate commands to the propellers and thrusters (pitch, revolutions per minute, azimuth, rudder angle) to counteract associated forces and maintain the rig in the desired position. A vital part of the DP system is the power supply. Diesel alternators, switchboards, cabling, propulsion motors and power management form part of the power system required for DP operations (Sørensen, 2011).

\subsection{DP drilling accidents}

As DP technology developed, it allowed the oil and gas industry to explore for hydrocarbons in deeper waters (Rokseth et al., 2017). This progress brought with it a number of challenges which involved the introduction of new operational guidance and the corresponding risk management. DP drilling incidents have been the subject of various lines of academic research. Chen et al. (2008) published a paper analysing the safety of DP operations based on a barrier model. These authors identified a range of problems that may arise in each watch circle excursion and established that only a DPO could avoid an incident by returning the unit to the position within the yellow watch circle, underlining the importance of this figure. Procedures for determining the trajectory of the vessel when an excursion takes place were studied by Bhalla and Cao (2005); their results can be used to improve drilling operations by estimating the disconnection times. Sanchez-Varela et al. (2021) proposed a model for predicting loss of position for DP drilling operations, where generators and meteorological conditions were the main factors influencing excursions.

\subsection{The human element}

Any maritime system is based on people (Endrina et al., 2019). The level of automation still depends on the figure of the system operator, namely, a person. Any operational failure has a strong component of human error (Abaei et al., 2019). When a DP system fails to keep the position, the DPO must take over and regain control over the degraded status of the system. For this, procedures are in place and following them allows safe recovery from an unexpected incident. Nonetheless, operators' skills and seamanship may be key for adapting procedures, optimising them to facilitate the return to a normal situation (Overgard et al., 2015). In this context, an additional challenge is the lack of trained and experienced staff to carry out DP operations (Rahman et al., 2019). 
A very interesting approach to analysing human factors in DP incidents using a Bayesian network was proposed by Chae (2015), and building on this work, the same research group applied a formal safety assessment to these factors, the nature of the human error being determined and some mitigating measures proposed (Chae, 2017). Further, Overgard et al. (2015) researched the human element during DP incidents considering different levels of situational awareness. On the other hand, Dong et al. (2017) concluded that most accidents during offshore loading operations are caused by a combination of human error and technical and organisational failures based on an approach using an event-and-cause diagram, change analysis (describing how the events deviated from common practice) and barrier analysis.

From all the above, the importance of human errors in DP operations has been established. This paper presents a new approach that analyses a range of weather and system configuration variables that might be associated with human factors involved in incidents. Specifically, a mathematical model that can predict the human nature of an incident is defined. Based on this model, operational limits can be proposed to improve the performance and safety of the operations.

The incidents focused on in this paper are the DP failures that happen during marine seabed drilling operations. The main objective of this paper is to find a mathematical expression that describes the probability of an incident during DP drilling operations having been caused by human error. Identifying which variables are associated with an incident being caused by human error and in what way may help pinpoint the riskiest situations and thereby make it possible to take steps to improve the safety of drilling operations. From the results obtained, it would be possible to propose operational limits to improve the safety of drilling operations.

\section{Material and methods}

The research team gathered data on incidents from the International Maritime Contractors Association (IMCA) station keeping event reports from 2011 to 2015. The incidents that took place while there were drilling operations in progress were selected, 50 cases in total. The data in the event tree were carefully extracted and a database was developed, including the variables shown in Table 1. Once the database had been created, some missing values were observed for some of the variables. The corresponding eight cases were eliminated to make the sample uniform, and this did not significantly influence the mean or median values calculated for the sample. Thus, the sample analysed consists of 42 cases.

This database was uploaded to the IBM SPSS Statistics for Windows, version 23·0, software. Descriptive statistics are calculated for each variable before developing binary logistic regression models. Logistic regression does not require data on the independent variables to be normally distributed (Sweet and Grace-Martin, 1999). Figure 1 is a descriptive diagram showing the variables taken into account for the regression modelling and their role during drilling operations.

\subsection{Binary logistic regression model}

A binary logistic regression technique is used to build a model that relates a categorical dependent variable and one or more independent variables, in such a way that the conditional probability of an event occurring is calculated (Kim et al., 2015). In this case, the dependent variable is human cause, and it will take a value of 0 if there is no human cause and 1 if there is a human cause. The rest of the variables are considered to be independent variables. Except for water depth, percentage of thrusters online, percentage of generators online, wind force, current speed and wave height, which are all quantitative, the independent variables are categorical. Given this, the program manipulates their values internally, in a way that produces as many variables as there are categories minus one. For example, there are five categories for wind sensors, and the program produces four variables: wind sensors $(i), i=1,2,3,4$.

Considering the values for each case in the independent variables, the program calculates the probability of a human cause for each of them. This probability varies between 0 and 1 ; the closer to 0 , the lower the probability of a human cause, and the closer to 1 , the higher the probability of a human cause. 
Table 1. Variables included in the analysis of DP drilling incidents, extracted from event trees for each DP incident reported.

\begin{tabular}{|c|c|}
\hline Variable & Description \\
\hline Year & Year in which the incident occurred \\
\hline Water depth (m) & $\begin{array}{l}\text { Depth of water at which the drilling operations took } \\
\text { place }\end{array}$ \\
\hline Percentage of thrusters online & $\begin{array}{l}\text { Number of thrusters online divided by the total } \\
\text { number of thrusters online and on standby }\end{array}$ \\
\hline Percentage of generators online & $\begin{array}{l}\text { Number of generators online, divided by the total } \\
\text { number of generators online and on standby }\end{array}$ \\
\hline DGNSS & $\begin{array}{l}\text { Number of DGNSS systems that are selected in the } \\
\text { DP system }\end{array}$ \\
\hline HPRs & $\begin{array}{l}\text { Number of hydroacoustic systems that are selected in } \\
\text { the DP system }\end{array}$ \\
\hline Taut wires & Number of taut wires in use during the operations \\
\hline Inertia systems & $\begin{array}{l}\text { Number of inertia systems in use during the drilling } \\
\text { operations }\end{array}$ \\
\hline Gyros & Number of gyros in use during the drilling operations \\
\hline MRUs & Number of MRUs in use during the drilling operations \\
\hline Wind sensors & $\begin{array}{l}\text { Number of wind sensors in use during the drilling } \\
\text { operations }\end{array}$ \\
\hline Wind force (in knots) & Force of the wind blowing when the incident happened \\
\hline Current speed (in knots) & Speed of the current when the incident happened \\
\hline Wave height (m) & Height of the waves when the incident happened \\
\hline Visibility & $\begin{array}{l}\text { Visibility when the incident happened categorised as } \\
\text { follows: poor, }<2 \mathrm{~nm} \text {; moderate, } 2-5 \mathrm{~nm} \text {; and good, } \\
>5 \mathrm{~nm} \text { (Met Office, 2020) }\end{array}$ \\
\hline Main cause & $\begin{array}{l}\text { The leading cause, as defined in the classification } \\
\text { presented by the IMCA }\end{array}$ \\
\hline Secondary cause & $\begin{array}{l}\text { The secondary cause, if present, as defined in the } \\
\text { classification presented by the IMCA }\end{array}$ \\
\hline Excursion & Whether or not an excursion took place \\
\hline Human cause & $\begin{array}{l}\text { When either the main or secondary causes have a } \\
\text { human origin, then } 1 \text { is entered; otherwise, } 0 \text { is } \\
\text { inserted indicating no human cause }\end{array}$ \\
\hline Period & $\begin{array}{l}\text { The first period is from } 2011 \text { to } 2013 \text { and the second } \\
\text { from } 2013 \text { to } 2015\end{array}$ \\
\hline
\end{tabular}

In this way, each case is assigned a probability $P$. This is important in order to interpret the coefficients in the regression.

The variables are selected by the chosen method: forward Wald. This method is based on adding or removing variables from the model by using two statistics: the score of Rao and the Wald statistic. The score of Rao allows comparison for each independent variable $X j$ with the null hypothesis: $\mathrm{Ho}=\beta j=0$; that is, the parameter associated to the variable in the model is null. The variable that presents the minimum associated $P$-value, always less than $0 \cdot 05$, for the statistic will be selected to enter the model. Also for the Wald statistic the null hypothesis can be compared Ho: $\beta j=0$, but in this case it is for the independent values that are already selected and have entered the model. A variable with a $P$-value 


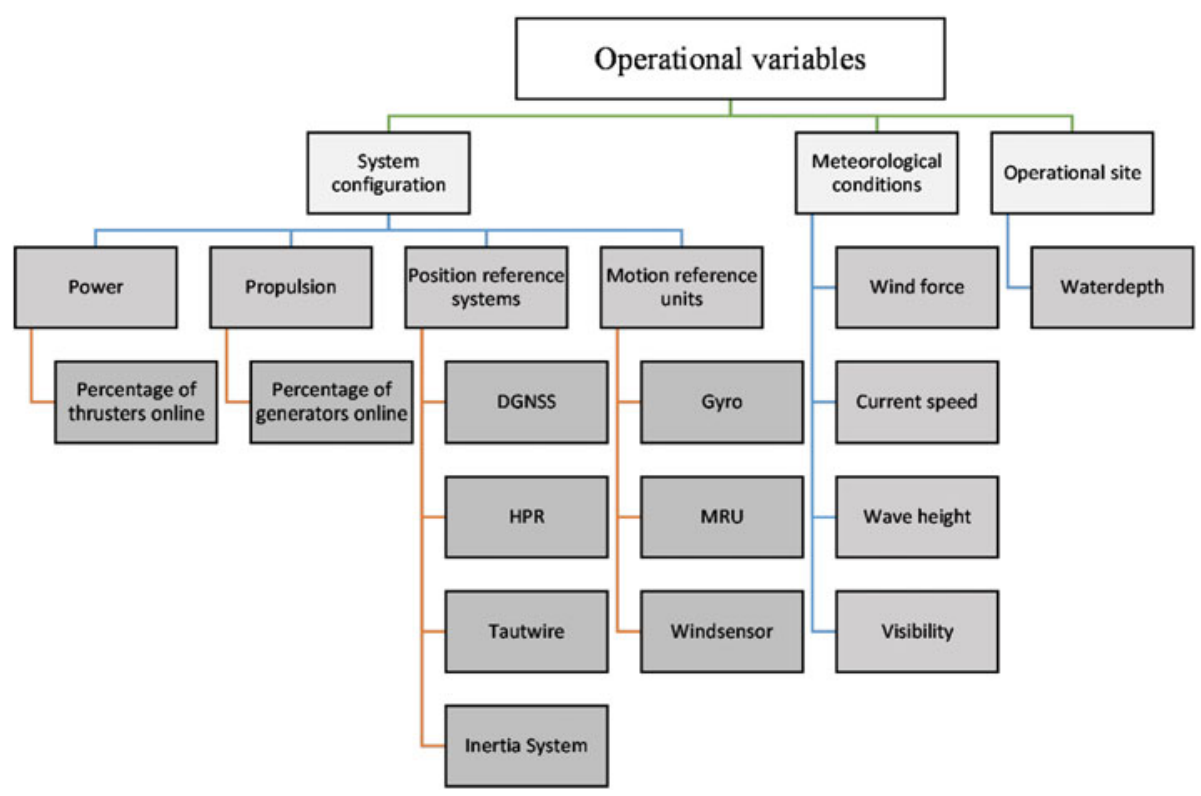

Figure 1. Variables considered in the logistic regression modelling classified according to their role during DP drilling operations.

associated to the Wald statistic greater than $0 \cdot 1$ will be eliminated, as this is by default the option of the program (POUT(.10)).

There will be several steps in which independent variables will be entered and eliminated, according to the criteria exposed above. At step 0, only the constant is introduced to the model. For this constant, it is important to measure $B$, the estimated standard error in the estimation, the Wald statistic and its degrees of freedom and associated $P$-value. When this $P$-value is less than $0 \cdot 1$, the constant is considered to be significant.

At step 0 , all the independent variables are out of the model. One variable has to be selected to enter the model in step 1 . The variable with the smallest $P$-value associated to the score which is less than 0.05 will be selected. It should be noted that the variables created from a categorical variable should be considered as a whole. In the case of two or more variables having the same $P$-value, the Rao score should then be considered, choosing the variable with the bigger score to enter the model in step 1 .

For the variables in the equation, which are already in the model, we should study the Wald statistic, given by:

$$
\text { Wald }=(B / S . E .)^{2}
$$

If its $P$-value is greater than $0 \cdot 1$ (output value, POUT), the corresponding variable would be eliminated (as a whole in the case of the categorical variables). It is always eliminated before the new variable is selected.

The system will examine the need to add or delete a variable until no further improvements can be made.

\subsection{Mathematic model}

The equation of the model is given by

$$
Z=B_{1} X_{1}+\ldots+B_{k} X_{k}+B_{0}
$$


where $Z$ is the linear predictor function to determine the excursion of the incident, $X_{1}, \ldots, X_{k}$ represent each independent variable, $k$ being the number of independent variables, and $B_{0}, B_{1}, \ldots, B_{k}$ are the regression coefficients that must be estimated.

Transforming Equation (1), we can obtain the function that gives the likelihood of an incident having been caused by human error:

$$
P=1 /\left(1+e^{-Z}\right)
$$

In this way, the probability for each case can be obtained. A probability value of less than $0 \cdot 5$ indicates that the model predicts this case not to have been caused by human error and a value of more than 0.5 indicates that it predicts the case to have been caused by human error (while cases obtaining a probability value of 0.5 are unclassifiable and hence eliminated).

To determine whether the prediction of the model is accurate, it needs to be validated. The validation is based on observing the actual cause of a case incident and comparing it with the prediction from the proposed model. If the predicted and actual cause match, then it is said that the model has good predictive power. Furthermore, considering the dynamic nature of the incidents, the model should be validated in two different periods. The model should not only include the same independent variables with no significant changes in their coefficients but also maintain the rate of prediction if it is to be considered valid for use. The model is then validated by comparing the accuracy in two different periods. Due to the size of the sample, the different periods overlap.

\subsection{Goodness of fit}

The likelihood of an incident having been caused by human error or not has been estimated, but this does not necessarily match the real cause; that is, according to the model, the case may have a significantly greater probability of belonging to the first group (no human cause) and yet belong to the second group (human cause). Assessing goodness of fit involves checking how probable the results obtained for the estimated model are. This is based on comparing the number of cases that belong to the second group (human cause) with the number expected if the model were to be valid. This expected number is the total number of cases in the sample multiplied by the estimated probability of belonging to the second group. When the percentage of the correctly classified cases is high, it is expected to provide good results when predicting whether or not an incident has a human cause.

The difference between the observed probability ( $P$ observed) and the estimated probability ( $P$ estimated), the error, is given by $E_{i}$ :

$$
E_{i}=P \text { observed }_{i}-P \text { estimated }_{i}
$$

where $E_{i}$ can take values in the range $(-1,1) . E_{i}$ will take a value of zero if human error is both the estimated and the observed cause. Studying the dispersion of the errors of the model, the goodness of fit can be evaluated.

\section{Results}

All 42 cases were included in the analysis. There were nine incidents with a human cause, $21 \%$ of the total. The rest had other causes, such as environmental conditions, thruster/propulsion failure or power failure. The statistical description of the independent variables is shown in Table 2.

As a first step, the variables are introduced in the model one by one to check their significance in the model describing the possibility of an incident being caused by a human error. When a variable is considered individually in the model, we can observe its influence in the model without interference from other factors. The significance of the variable is thus highest when it is considered individually. This step is considered useful as the variables without any significance can be eliminated at this stage, and in this way the process of creating the model can be simplified. Except for the percentage of thrusters, 
Table 2. Statistical description of the independent variables included in the study.

\begin{tabular}{lcc}
\hline Variables & Mean & Standard Error \\
\hline Water depth (m) & $1409 \cdot 238$ & $112 \cdot 0642$ \\
Percentage of thrusters (\%) & $92 \cdot 55$ & $2 \cdot 341$ \\
Percentage of generators (\%) & $64 \cdot 5125$ & $3 \cdot 47436$ \\
DGNSS (no. of units) & $2 \cdot 33$ & $0 \cdot 121$ \\
HPR (no. of units) & $1 \cdot 40$ & $0 \cdot 103$ \\
Taut wire (no. of units) & $0 \cdot 12$ & $0 \cdot 061$ \\
Inertia system (no. of units) & $0 \cdot 05$ & $0 \cdot 033$ \\
Gyros (no. of units) & $3 \cdot 00$ & $0 \cdot 034$ \\
MRU (no. of units) & $2 \cdot 90$ & $0 \cdot 046$ \\
Wind sensors (no. of units) & $2 \cdot 83$ & $0 \cdot 102$ \\
Wind force (knots) & $16 \cdot 005$ & $1 \cdot 8750$ \\
Current speed (knots) & $1 \cdot 895$ & $0 \cdot 2266$ \\
Wave height (m) & $1 \cdot 879$ & $0 \cdot 2976$ \\
Visibility (category) & $2 \cdot 619$ & $0 \cdot 961$ \\
\hline
\end{tabular}

Table 3. Main statistics obtained for the variable percentage of thrusters when applying Forward Wald for binary regression modelling.

\begin{tabular}{lrrrcrr}
\hline Variable & B & S.E. & Wald & Degrees of freedom & Sig. & Exp(B) \\
\hline Percentage of thrusters & -0.094 & 0.029 & $10 \cdot 289$ & 1 & 0.001 & 0.910 \\
Constant & 7.053 & 2.612 & 7.289 & 1 & 0.007 & 1156.017 \\
\hline
\end{tabular}

the other variables did not meet the criteria for inclusion in the equation for determining the likelihood of an incident having been caused by human error. The table showing the main statistics for the variable included in the model are shown in Table 3. Given this outcome, only the percentage of thrusters is taken into account in the model.

The following expression defines the model:

$$
Z=7 \cdot 053-0 \cdot 094 \cdot \text { Percentage of thrusters }
$$

\subsection{Model validation}

It is observed that the proposed model correctly classifies 31 incidents as not having been caused by human error (94\%), and six incidents as having been caused by human error (67\%). Overall, the number of correctly predicted incidents is 37 out of 42 , yielding an accuracy of $88 \%$. This can be considered a very good prediction.

In the first period, 2011 to 2013, the model proposed when regression modelling is applied to the reduced sample is:

$$
Z=7 \cdot 543-0 \cdot 104 \cdot \text { Percentage of thrusters }
$$

When this model is tested in the selected sample for the first period, composed of 17 incidents, 16 were correctly classified (94\% accuracy). The model correctly classified all 15 incidents without a human cause (100\%), and one out of two incidents with a human cause $(50 \%)$. 


\section{Error dispersion}

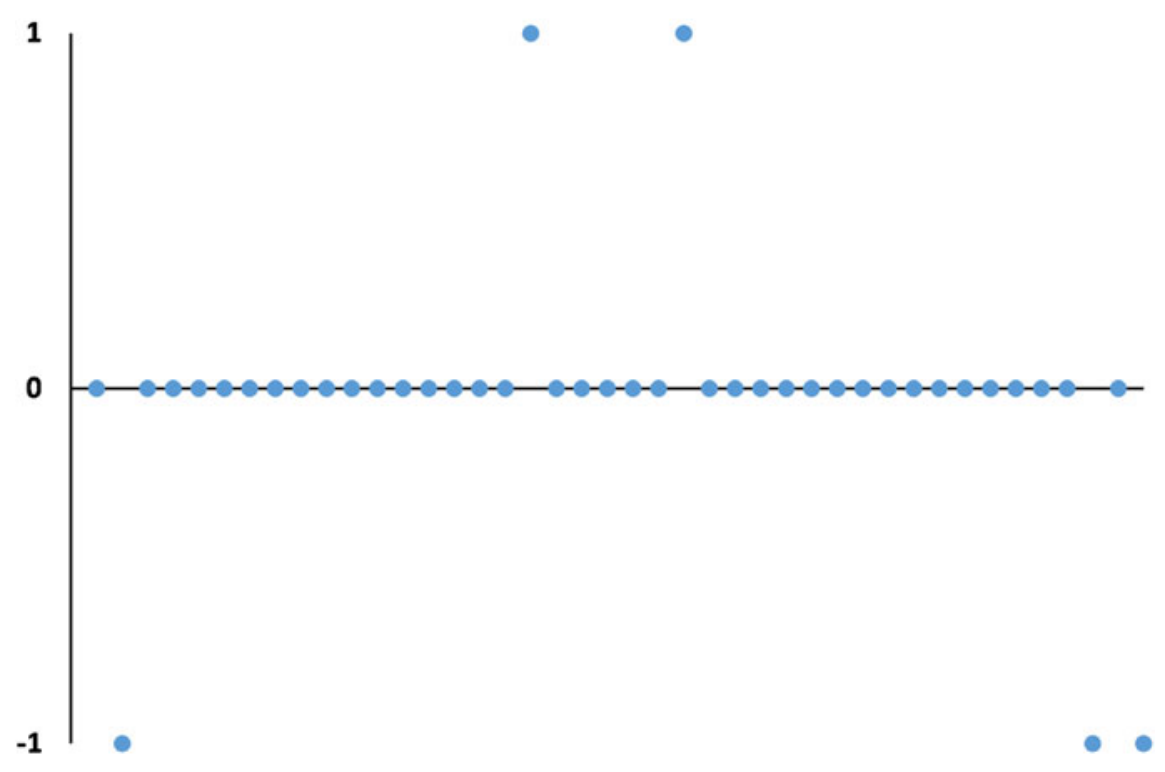

Figure 2. Distribution of the errors found during the validation of the model, where 0 shows no error, 1 indicates an incident that was incorrectly classified as caused by human error, and -1 indicates an incident incorrectly classified as no human cause.

In the second period, 2013 to 2015 , the same technique is applied to the 34-case incident sample, obtaining the proposed model:

$$
Z=7 \cdot 144-0 \cdot 097 \text { Percentage of thrusters }
$$

This model is able to classify 30 incidents (88\%) correctly, correctly classifying 25 out of 27 incidents without a human cause (93\% accuracy), and four out of seven incidents with a human cause (57\%). This rate of correctly classified human-caused incidents is higher when the model for the complete sample [Equation (4)] is applied to the sample for the second period, five out of seven incidents being correctly classified $(71 \%)$.

Finally, the error dispersion is analysed, showing the vast majority of errors lie on the horizontal axis (error of zero), as shown in Figure 2. This distribution indicates that the model is mostly not producing errors.

\subsection{Model application}

Having validated the model, it can be considered to make very good predictions when applied during normal operations. In order to explore the practical application of the model, the odds for the different percentage of thrusters online (in steps of 10) were calculated, as shown in Table 4. The likelihood of an incident having been caused by human error decreases as the percentage of thrusters increases. Specifically, when more than $70 \%$ of thrusters are online, the odds show that the likelihood of a humancaused incident is low, while for thruster percentages below 50\%, the odds show that there is a $90 \%$ likelihood of a human cause underlying an incident, as shown in Figure 3.

\section{Discussion}

The research presented in this paper aimed to develop a model that would calculate the likelihood of an incident having been caused by human error while DP drilling operations are in progress. The results 


\section{Likelihood of human cause depending on percentage of thrusters}

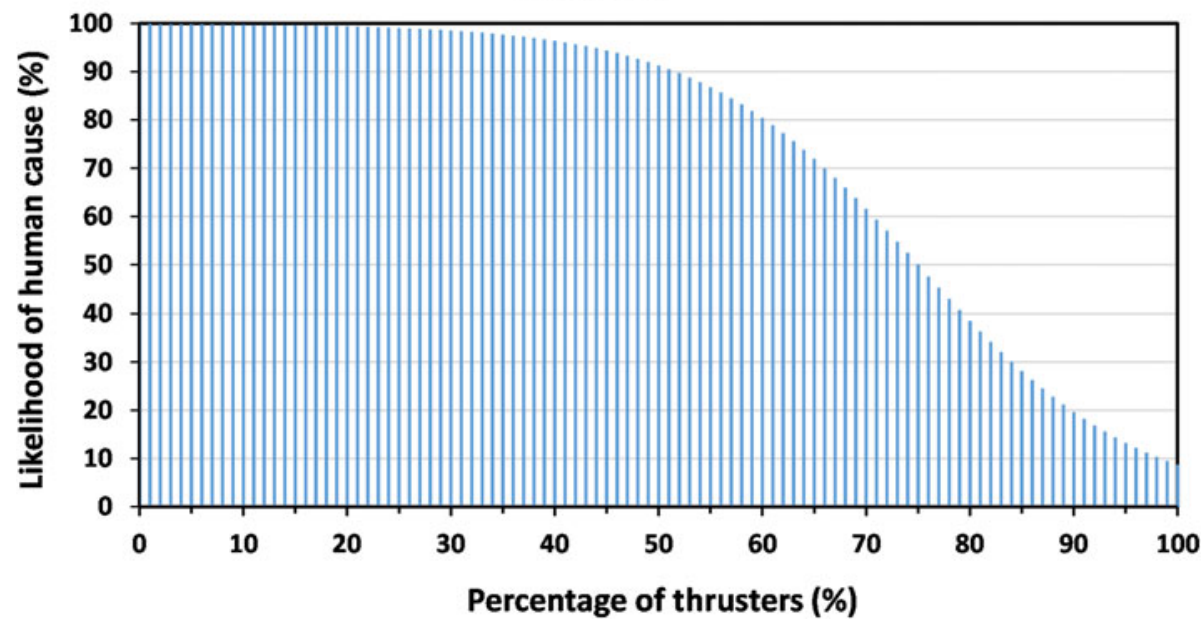

Figure 3. Likelihood of an incident having been caused by human error, according to the model proposed, for different percentages of thrusters.

Table 4. Calculation of the likelihood of human cause when applying the mathematical model as in Equation (5), for different values of the percentage of thrusters.

\begin{tabular}{lcc}
\hline Percentage of thrusters $(\%)$ & $Z$ & Likelihood of human cause $(\%)$ \\
\hline 0 & $7 \cdot 053$ & $99 \cdot 91$ \\
10 & $6 \cdot 113$ & $99 \cdot 78$ \\
20 & $5 \cdot 173$ & $99 \cdot 44$ \\
30 & $4 \cdot 233$ & $98 \cdot 57$ \\
40 & $3 \cdot 293$ & $96 \cdot 42$ \\
50 & $2 \cdot 353$ & $91 \cdot 32$ \\
60 & $1 \cdot 413$ & $80 \cdot 42$ \\
70 & $0 \cdot 473$ & $61 \cdot 61$ \\
80 & $-0 \cdot 467$ & $38 \cdot 53$ \\
90 & $-1 \cdot 407$ & $19 \cdot 67$ \\
100 & $-2 \cdot 347$ & $8 \cdot 73$ \\
\hline
\end{tabular}

provide a model based on the percentage of thrusters online as a function of the total number of thrusters, as the only variable among all those considered that may influence whether an accident is caused by human error.

It is clear that the source of data on incidents used does not provide a complete list of all the incidents happening during DP drilling operations. Nonetheless, it can be considered a good worldwide database, backed by the IMCA. The number of incidents and near-misses reported by offshore workers may be influenced by numerous external and internal factors (e.g., pressure to achieve efficiency), according to research carried out by Kongsvik et al. (2012), and underreporting of incidents (Psarros et al., 2010).

In the reports provided by the IMCA, data are presented on a vast number of variables, both for meteorological conditions (wind, current, visibility) and the configuration of the system (such as number of thrusters online/offline, number of generators online/offline, number of gyros and number of PRS). On the other hand, the specific DP systems in use are not detailed in the incident reports; this limitation 
should be taken into account when applying the results of this research, as different DP systems may have different responses to an eventual loss of position. Similarly, knowing the type of thrusters and their layout onboard the vessel could allow a better understanding of the behaviour of each incident, as explained by Mauro and Prpić-Oršić (2020). Nonetheless, the results obtained are very significant and meet the objectives set in this paper.

Specifically, we have found that an incident occurring when operating with a low percentage of thrusters online tends to increase the likelihood of such an incident being caused by human error. These human errors are mainly the result of individuals not following the established procedures in the event of loss of position. It is usual that, in the event of a loss of position, the DPO takes manual control of the system. It seems plausible to suppose that there being a larger number of thrusters online could help to reduce the magnitude of the excursion, allowing the DPO to respond more quickly and be more aware of the situation when taking over the control.

The significance of the model $(P$-value $<0 \cdot 05)$ indicates the robustness of the proposed mathematical expression, and provides strong evidence that the selected variable influences the causality of the incident. No other independent variable tested sufficiently enhanced the model to warrant inclusion. However, it is important to discuss the differences between the obtained results and similar incidents in the literature, such as Marine Insight (2020). In these incidents, the percentage of thrusters is commonly presented as a mere piece of information, but rarely as a direct trigger of the incident.

The validation of the model shows that it does not significantly change over time when considering two different periods. Indeed, it is capable of improving the prediction of human-caused incidents, giving very good results. As such, the model could be proposed for application in industry. In order to be useful for operators, the odds were calculated for different percentages of thrusters online, and the results indicate that having fewer than $50 \%$ of thrusters online is associated with human errors ending in an incident.

\section{Conclusions}

The results of this study indicate that human-caused incidents occurring during DP drilling operations are strongly influenced by the percentage of thrusters online as a function of the total number of thrusters on board. The lower the percentage of thrusters, the greater the likelihood of a human error underlying any incident. Applying the proposed model, it is evidenced that implementing an operational limit of not less than $50 \%$ of thrusters online could help to reduce the risk of human factors, thereby improving safety during DP drilling operations.

Funding statement. This research received no specific grant from any funding agency, commercial or not-for-profit sectors.

Competing interest. The authors declare that there are no conflicts of interest regarding the publication of this paper.

\section{References}

Abaei, M. M., Abbassi, R., Garaniya, V., Arzaghi, E. and Bahoo Toroody, A. (2019). A dynamic human reliability model for marine and offshore operations in harsh environments. Ocean Engineering, 173, 90-97.

Acejo, I., Sampson, H., Turgo, N., Ellis, N. and Tang, L. (2018). The Causes of Maritime Accidents in the Period $2002-2016$. 1-15. Seafarers International Research Centre, Cardiff University, Cardiff, UK.

Agarwal, S., Kachroo, P. and Regentova, E. (2016). A hybrid model using logistic regression and wavelet transformation to detect traffic incidents. IATSS Research, 40(1), 56-63.

Ancione, G., Bragatto, P. and Milazzo, M. F. (2020). A Bayesian network-based approach for the assessment and management of ageing in major hazard establishments. Journal of Loss Prevention in the Process Industries, 64, 104080.

Arnaldo Valdes, R. M., Liang Cheng, S. Z. Y., Gomez Comendador, V. F. and Saez Nieto, F. J. (2018). Application of Bayesian networks and information theory to estimate the occurrence of mid-air collisions based on accident precursors. Entropy, 20(12), 969.

Bhalla, K. and Cao, Y. (2005). Watch Circle Assessment of Drilling Risers During a Drift-Off and Drive-Off Event of a Dynamically Positioned Vessel. MTS Dynamic Positioning Conference, Houston, TX.

Bier, V. M. and Mosleh, A. (1990). The analysis of accident precursors and near misses: Implications for risk assessment and risk management. Reliability Engineering and System Safety, 27, 91-101. 
Bier, V. M. and Yi, W. (1995). The performance of precursor-based estimators for rare event frequencies. Reliability Engineering and System Safety, 50, 241-251.

Boullosa-Falces, D., Barrena, J. L. L., Lopez-Arraiza, A., Menendez, J. and Solaetxe, M. A. G. (2017). Monitoring of fuel oil process of marine diesel engine. Applied Thermal Engineering, 127, 517-526.

Bray, D. (2018). DP Operations. Part 2 - What Is DP Used for? London: Seaways. The Nautical Institute.

Bray, D., Daniels, J., Fiander, G. and Foster, D. (2015). DP Operator's Handbook. London: The Nautical Institute.

Chae, C. (2015). A study on human error of DP vessels LOP incidents. Journal of the Korean Society of Marine Environment \& Safety, 21(5), 515-523.

Chae, C. (2017). A study on FSA application for human errors of dynamic positioning vessels incidents. Journal of Korean Navigation and Port Research, 41(5), 259-268.

Chen, H., Moan, T. and Verhoeven, H. (2008). Safety of dynamic positioning operations on mobile offshore drilling units. Reliability Engineering \& System Safety, 93(7), 1072-1090.

Dong, Y., Vinnem, J. E. and Utne, I. B. (2017). Improving safety of DP operations: Learning from accidents and incidents during offshore loading operations. Euro Journal on Decision Processes, 5(1-4), 5-40.

Endrina, N., Konovessis, D., Sourina, O. and Krishnan, G. (2019). Influence of ship design and operational factors on human performance and evaluation of effects and sensitivity using risk models. Ocean Engineering, 184, 143-158.

Erjavac, A. J., Iammartino, R. and Fossaceca, J. M. (2018). Evaluation of preconditions affecting symptomatic human error in general aviation and air carrier aviation accidents. Reliability Engineering \& System Safety, 178, 156-163.

Erol, S., Demir, M., Çetişli, B. and Eyüboğlu, E. (2018). Analysis of ship accidents in the Istanbul Strait using neuro-fuzzy and genetically optimised fuzzy classifiers. The Journal of Navigation, 71(2), 419-436.

Fiskin, R., Cakir, E. and Sevgili, C. (2020). Decision tree and logistic regression analysis to explore factors contributing to harbour tugboat accidents. The Journal of Navigation, 74(1), 1-26.

Hogenboom, S., Rokseth, B., Vinnem, J. E. and Utne, I. B. (2020). Human reliability and the impact of control function allocation in the design of dynamic positioning systems. Reliability Engineering \& System Safety, 194, 106340.

Kalantarnia, M., Khan, F. and Hawboldt, K. (2010). Modelling of BP Texas City refinery accident using dynamic risk assessment approach. Process Safety and Environmental Protection, 88(3), 191-199.

Kariuki, S. G. and Löwe, K. (2007). Integrating human factors into process hazard analysis. Reliability Engineering \& System Safety, 92(12), 1764-1773.

Khakzad, N., Khakzad, S. and Khan, F. (2014). Probabilistic risk assessment of major accidents: Application to offshore blowouts in the Gulf of Mexico. Natural Hazards, 74(3), 1759-1771.

Khan, F. I. and Abbasi, S. A. (1998). Techniques and methodologies for risk analysis in chemical process industries. Journal of Loss Prevention in the Process Industries, 11(4), 261-277.

Kim, Y., Park, J., Jung, W., Jang, I. and Hyun Seong, P. (2015). A statistical approach to estimating effects of performance shaping factors on human error probabilities of soft controls. Reliability Engineering \& System Safety, 142, 378-387.

Kongsvik, T., Fenstad, J. and Wendelborg, C. (2012). Between a rock and a hard place: Accident and near-miss reporting on offshore service vessels. Safety Science, 50(9), 1839-1846.

Kristiansen, S. (ed.). (2005). Maritime Transportation: Safety Management and Risk Analysis. London: Elsevier ButterworthHeinemann.

Levine, S. and Rasmussen, N. C. (1984). Nuclear plant PRA: How far has it come. Journal of Risk Analysis, 4, $247-254$.

Li, R., Pereira, F. C. and Ben-Akiva, M. E. (2015). Competing risks mixture model for traffic incident duration prediction. Accident Analysis and Prevention, 75, 192-201.

Manca, D. and Brambilla, S. (2012). Dynamic simulation of the BP Texas City refinery accident. Journal of Loss Prevention in the Process Industries, 25(6), 950-957.

Mao, L., Zeng, S. and Liu, Q. (2019). Dynamic mechanical behavior analysis of deep water drilling riser under hard hang-off evacuation conditions. Ocean Engineering, 183, 318-331.

Marine Insight. (2020). Real Life Incident: Human Error Causes Loss of Power on DP Vessel. Available at: https://www. marineinsight.com/case-studies/dp-mishap-human-error-total-loss-power/ [Accessed 20 Feb. 2021].

Mauro, F. and Prpić-Oršić, J. (2020). Determination of a DP operability index for an offshore vessel in early design stage. Ocean Engineering, 195, 106764.

McFadden, K. L. (1997). Predicting pilot-error incidents of US airline pilots using logistic regression. Applied Ergonomics, 28(3), 209-212.

Met Office. (2020). Marine Forecasts Glossary. Available at: https://www.metoffice.gov.uk [Accessed 5 Jan. 2020].

Mkrtchyan, L., Podofillini, L. and Dang, V. N. (2015). Bayesian belief networks for human reliability analysis: A review of applications and gaps. Reliability Engineering \& System Safety, 139, 1-16.

Overgard, K. I., Sorensen, L. J., Nazir, S. and Martinsen, T. J. (2015). Critical incidents during dynamic positioning: Operators' situation awareness and decision-making in maritime operations. Theoretical Issues in Ergonomics Science, 16(4), 366-387.

Psarros, G., Skjong, R. and Eide, M. S. (2010). Under-reporting of maritime accidents. Accident Analysis \& Prevention, 42(2), $619-625$

Rahman, M. S., Khan, F., Shaikh, A., Ahmed, S. and Imtiaz, S. (2019). Development of risk model for marine logistics support to offshore oil and gas operations in remote and harsh environments. Ocean Engineering, 174, 125-134. 
Rebello, S., Yu, H. and Ma, L. (2019). An integrated approach for real-time hazard mitigation in complex industrial processes. Reliability Engineering \& System Safety, 188, 297-309.

Rokseth, B., Utne, I. B. and Vinnem, J. E. (2017). A systems approach to risk analysis of maritime operations. Proceedings of the Institution of Mechanical Engineers, Part O: Journal of Risk and Reliability, 231(1), 53-68.

Sanchez-Varela, Z., Boullosa-Falces, D., Larrabe-Barrena, J. L. and Gomez-Solaeche, M. A. (2021). Prediction of loss of position during dynamic positioning drilling operations using binary logistic regression modeling. Journal of Marine Science and Engineering, 9(2), 139.

Shengli, L. and Yongtu, L. (2019). Exploring the temporal structure of time series data for hazardous liquid pipeline incidents based on complex network theory. International Journal of Critical Infrastructure Protection, 26, 100308.

Singh, B., Jukes, P., Poblete, B. and Wittkower, B. (2010). 20 years on lessons learned from Piper Alpha. The evolution of concurrent and inherently safe design. Journal of Loss Prevention in the Process Industries, 23(6), 936-956.

Sørensen, A. J. (2011). A survey of dynamic positioning control systems. Annual Reviews in Control, 35(1), 123-136.

Sweet, S. A. and Grace-Martin, K. (1999). Data Analysis with SPSS. Boston, MA: Allyn \& Bacon.

The Nautical Institute. (2017). Accreditation and Certification Scheme Standard. London.

Theophilus, S. C., Esenowo, V. N., Arewa, A. O., Ifelebuegu, A. O., Nnadi, E. O. and Mbanaso, F. U. (2017). Human factors analysis and classification system for the oil and gas industry (HFACS-OGI). Reliability Engineering \& System Safety, 167, 168-176.

U.S. Bureau of Safety and Environmental Enforcement (2019). Panel Investigation Reports. U.S. Department of the Interior, Bureau of Safety and Environmental Enforcement. Available at: https://www.bsee.gov/what-we-do/incident-investigations/ [Accessed 5 Dec. 2020].

Weng, J., Li, G., Chai, T. and Yang, D. (2018). Evaluation of two-ship collision severity using ordered probit approaches. The Journal of Navigation, 71(4), 822-836.

Yang, M., Khan, F., Lye, L. and Amyotte, P. (2015). Risk assessment of rare events. Process Safety and Environmental Protection, 98, 102-108.

Cite this article: Sanchez-Varela Z, Boullosa-Falces D, Larrabe-Barrena JL, Gomez-Solaeche MA (2021). Determining the likelihood of incidents caused by human error during dynamic positioning drilling operations. The Journal of Navigation 74: 4, 931-943. https:/doi.org/10.1017/ S0373463321000291 